\title{
Knoxdaviesia proteae is not the only Knoxdaviesia-symbiont of Protea repens
}

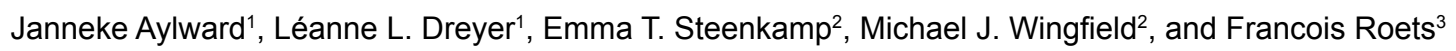

1Department of Botany and Zoology, Stellenbosch University, Private Bag X1, Matieland 7602, South Africa; corresponding author e-mail: janneke@sun.ac.za

${ }^{2}$ Department of Microbiology and Plant Pathology, University of Pretoria, Pretoria 0002, South Africa

${ }^{3}$ Department of Conservation Ecology and Entomology, Stellenbosch University, Private Bag X1, Matieland 7602, South Africa

\begin{abstract}
Two polyphyletic genera of ophiostomatoid fungi are symbionts of Proteaceae in southern Africa. One of these, Knoxdaviesia, includes two closely related species, $K$. proteae and $K$. capensis, that have overlapping geographical distributions, but are not known to share Protea host species. Knoxdaviesia capensis appears to be a generalist that occupies numerous hosts, but has never been found in $P$. repens, the only known host of $K$. proteae. In this study, extensive collections were made from $P$. repens and isolates were identified using DNA sequence comparisons. This led to the surprising discovery of $K$. capensis from $P$. repens for the first time. The fungus was encountered at a low frequency, suggesting that $P$. repens is not its preferred host, which may explain why it has not previously been found on this plant. The basis for the specialisation of $K$. proteae and $K$. capensis on different Protea species remains unknown.
\end{abstract}

\author{
Key words: \\ Gondwanamycetaceae \\ infructescence \\ ophiostomatoid fungi \\ South Africa
}

Article info: Submitted: 9 December 2014; Accepted: 28 September 2015; Published: 10 November 2015.

\section{INTRODUCTION}

Ophiostomatoid fungi are a polyphyletic assemblage (Spatafora \& Blackwell 1994, Wingfield et al. 1999) that share morphological characters such as flask-shaped ascomata with long necks bearing sticky spore droplets, that make them ideally suited for arthropod-mediated dispersal (Wingfield et al. 1993). Species in two genera, Ophiostoma and Knoxdaviesia (Wingfield et al. 1999), occur in the flower heads (infructescences) of serotinous Protea species in southern Africa (Fig. 1). They are not associated with disease symptoms on their hosts but could benefit the plant by excluding harmful fungi from the infructescences that must protect viable seeds for long periods of time (Roets et al. 2013).

The dispersal biology of Protea-associated ophiostomatoid fungi is intriguing. The primary vectors are mites (Roets et al. 2011b) that have a mutualistic association with some of the fungi they carry (Roets et al. 2007). These mites can self-disperse to other infructescences on a Protea tree, but most often they use beetles as long-distance vectors to reach other Protea trees (Aylward et al. 2014a, Roets et al. 2009a). Although the vectors of the Protea-associated ophiostomatoid species are the same, the various fungal species display distinct patters of affinity for their host Protea species (Roets et al. 2005, 2011b). For example, the closely related species $K$. capensis and $K$. proteae have overlapping geographic distributions and similar vectors, yet they have never been encountered together on the same Protea host
(Wingfield et al. 1988, 1999, Wingfield \& van Wyk 1993). Knoxdaviesia proteae consistently inhabits $P$. repens infructescences and it has not been found in other Protea species. In contrast, $K$. capensis occurs in at least eight different Protea species including $P$. burchelli, $P$. coronata, $P$. laurifola, $P$. lepidocarpodendron, $P$. longifolia, $P$. magnifica, $P$. neriifolia and $P$. obtusifolia, but has never been found in $P$. repens (Marais \& Wingfield 1994, Roets et al. 2005, 2011a, Wingfield \& van Wyk 1993).

The reason for the difference in host specificity between $K$. capensis and $K$. proteae is unknown. One possibility is that this separation prevents inter-specific competition between these fungi, given that they appear to rely on similar nutritional resources and occupy similar niches. Separation through host-exclusivity could, therefore, have been key to reduce competition and promote speciation (Giraud et al. 2008). Inter-species competition could also be avoided through temporal separation (succession) of colonization by ophiostomatoid species (Roets et al. 2013), although there is no evidence to support this view. The apparent host separation in the Knoxdaviesia species stands in contrast to some Protea-associated Ophiostoma species, which often co-occur with $K$. capensis or $K$. proteae in a single infructescence (Roets et al. 2006, 2013).

The host specificities of these Knoxdaviesia species are based on numerous randomly made collections of these fungi for taxonomic and biological studies. There has, however, never been a large-scale and systematic survey that would provide confidence in the hypothesis that $K$. proteae is the

๑ 2015 International Mycological Association

You are free to share - to copy, distribute and transmit the work, under the following conditions:

Attribution: $\quad$ You must attribute the work in the manner specified by the author or licensor (but not in any way that suggests that they endorse you or your use of the work).

Non-commercial: $\quad$ You may not use this work for commercial purposes.

No derivative works: You may not alter, transform, or build upon this work.

For any reuse or distribution, you must make clear to others the license terms of this work, which can be found at http://creativecommons.org/licenses/by-nc-nd/3.0/legalcode. Any of the above conditions can be waived if you get permission from the copyright holder. Nothing in this license impairs or restricts the author's moral rights. 



B

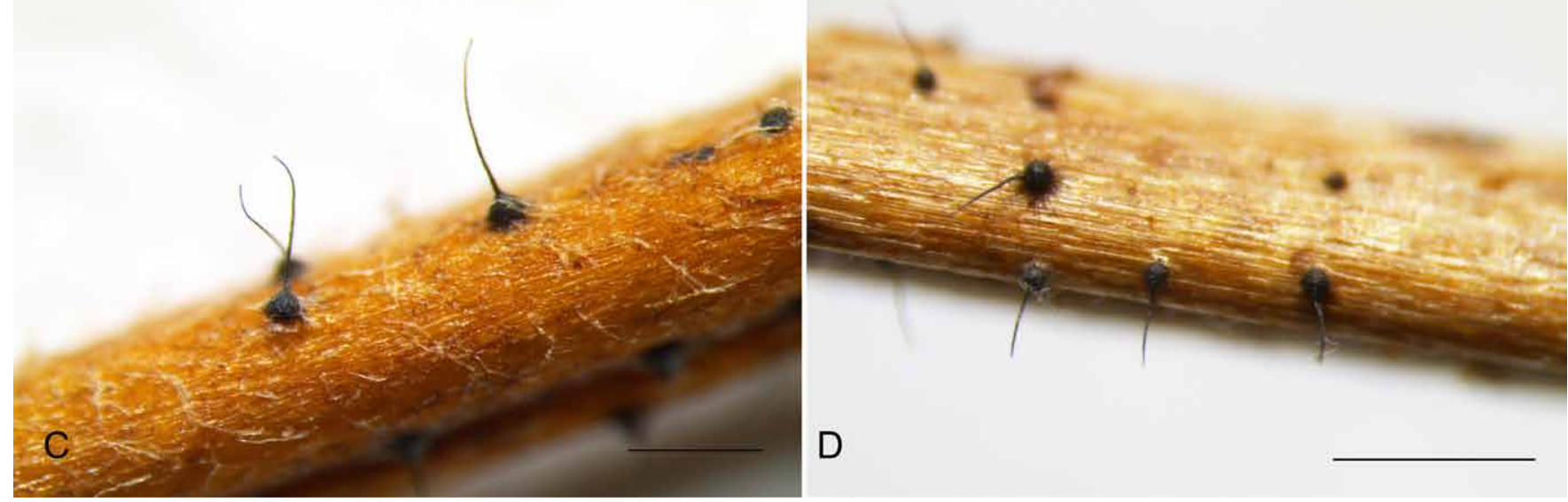

Fig. 1. A. Infructescences (brown cones) of Protea repens. B. Single Protea repens flower. C-D. Sexual sporing structures of Knoxdaviesia capensis (C) and K. proteae (D). Bars C-D $=0.5 \mathrm{~mm}$.

only Knoxdaviesia species occurring in $P$. repens. Isolations of Knoxdaviesia-like sporing structures were made from infructescences in two natural populations of $P$. repens. These were then used to test the hypothesis that $K$. proteae is the only Knoxdaviesia species that colonizes $P$. repens infructescences.

\section{MATERIALS AND METHODS}

During November 2012 and January 2013, infructescences were sampled from two Protea repens populations in the
Western Cape Province of South Africa (Table 1) in order to isolate $K$. proteae individuals as part of a previous study (Aylward et al. 2014a, 2015). In the Gouritz population $\left(34.2062^{\circ} \mathrm{S} 21.6812^{\circ} \mathrm{E}\right), 220$ infructescences from the current and 220 from the previous flowering seasons were sampled from 11 different $P$. repens trees (Aylward et al. 2014a). The site at Franschhoek (33.9044 $\left.{ }^{\circ} \mathrm{S} 19.1566^{\circ} \mathrm{E}\right)$ had been burnt in 2007, and was sampled just after the new $P$. repens recruits had flowered for the first time. Some $P$. repens trees at this site (ca 15-yr-old) had escaped the fire and were included in our surveys. At this site, 20 infructescences were collected from 11 plots (20 m diam) in the burnt area and 
Table 1. Knoxdaviesia capensis isolates obtained from Protea repens.

\begin{tabular}{|c|c|c|}
\hline Knoxdaviesia capensis isolate & Sampling location & GenBank ITS accession \\
\hline G024 & Gouritz & KP263518 \\
\hline G025 & “ & KP263519 \\
\hline G027 & “ & KP263520 \\
\hline G067 & “ & KP263521 \\
\hline G074 & “ & KP263522 \\
\hline G075 & “ & KP263523 \\
\hline G080 & “ & KP263524 \\
\hline G081 & “ & KP263525 \\
\hline G084 & “ & KP263526 \\
\hline G106 & “ & KP263527 \\
\hline F4.2 & Franschhoek & KP263528 \\
\hline F6.3 & “ & KP263529 \\
\hline F9.4 & “ & KP263530 \\
\hline F11.6 & “ & KP263531 \\
\hline $\mathrm{F} 12.3$ & “ & KP263532 \\
\hline $\mathrm{F} 14.1$ & “ & KP263533 \\
\hline F16.1 $1^{a}$ & “ & KP263534 \\
\hline $\mathrm{F} 16.2^{\mathrm{a}}$ & “ & KP263535 \\
\hline $\mathrm{F} 16.7^{\mathrm{a}}$ & “ & KP263536 \\
\hline F16.8 ${ }^{a}$ & “ & KP263537 \\
\hline F16.9a & “ & KP263538 \\
\hline $\mathrm{F} 16.10^{\mathrm{a}}$ & “ & KP263539 \\
\hline F19.10 & “ & KP263540 \\
\hline $\mathrm{F} 27.2$ & “ & KP263541 \\
\hline F31.2 & “ & KP263542 \\
\hline R7 (CBS 140644) & " & KT970644 \\
\hline
\end{tabular}

a Sampling plot F16 yielded Knoxdaviesia capensis isolates, exclusively.

${ }^{\mathrm{b}}$ Representative isolate available from the CBS-KNAW Fungal Biodiversity Centre, Utrecht, The Netherlands.

19 plots in the unburnt area (Aylward et al. 2015). Since the initial aim of the sampling was to collect $K$. proteae, only one Knoxdaviesia isolate was maintained per infructescence to prevent repeated isolation of the same individual. Because the sexual morphs of both $K$ proteae and $K$. capensis species are indistinguishable under $\times 30$ magnification (Fig. 1), fungal isolations were made from randomly selected sporing structures. Knoxdaviesia isolation methods and culturing techniques were as given in Aylward et al. (2014b). Isolates were identified by sequencing the ITS regions of the rDNA (White et al. 1990) as detailed by Aylward et al. (2014b).

Statistical analyses were conducted in $R$ v. 3.1.0 ( $R$ Core Team 2014). The number of fungal isolates obtained from infructescences at each sampling site (Gouritz or Franschhoek) and for each subdivision (flowering season or burnt/unburnt area) was recorded and tested for normality with Shapiro-Wilk's W test. Subsequently, a Mann-Whitney $U$ test for independent groups and a Pearson's Chi-square test was applied to test for significant differences between the numbers of isolates obtained from each infructescence age class (Gouritz population) and between the burnt and unburnt sampling plots (Franschhoek). These tests were chosen because the MannWhitney $U$ test takes into account only the number of positive hits (i.e. the presence of the fungus) whereas the Chi-square test also includes the total number of observations (i.e. number of infructescences sampled) (McKillup 2006).

A Maximum Likelihood ( $\mathrm{ML}$ ) phylogenetic tree was constructed in order to illustrate the difference between the species identified in this study. MAFFT 7 (Katoh \& Standley 2013) was used to align the ITS sequences of a subset of the isolated individuals to those of previously characterized species of Gondwanamycetaceae obtained from GenBank $\circledast$. The ML tree was computed in MEGA6 (Tamura et al. 2013) under the Tamura-Nei substitution model (Tamura \& Nei 1993) and reliability was calculated with 1000 bootstrap replications.

\section{RESULTS}

The intensive sampling effort yielded 224 Knoxdaviesia isolates -103 from the Gouritz and 121 from the Franschhoek population. Surprisingly, the ITS data used to identify the isolates (Aylward et al. 2014b) revealed that not all fungal strains collected were $K$. proteae, the only Knoxdaviesia species previously known to occur in $P$. repens (Fig. 2). The 




Knoxdaviesia proteae

Knoxdaviesia capensis

Fig. 2. Maximum Likelihood phylogenetic tree depicting the position of the two Knoxdaviesia species sampled from Protea repens infructescences. The final dataset consists of 474 characters. Knoxdaviesia proteae sequences are from the studies of Aylward et al. (2014a, 2015) and K. capensis sequences were generated in this study. "T" and "ET" indicate type and ex-type strains, respectively.

closely related $K$. capensis was also encountered, although at a low frequency. Ten $K$. capensis strains were isolated from four of the 11 different $P$. repens plants in the Gouritz population. In Franschhoek, $15 \mathrm{~K}$. capensis isolates were found in 10 of the 30 sampling plots, including six from a single plot in which $K$. proteae was not encountered (Table 1). Isolate R7 (CBS 140644) was deposited at the CBSKNAW Fungal Biodiversity Centre as a representative of $K$. capensis on $P$. repens. The sampling strategy did not enable co-occurrence of the two Knoxdaviesia species in one infructescence to be detected.

The Shapiro-Wilk's W tests for normality rejected the null hypothesis that the number of $K$. capensis isolates sampled from Gouritz ( $\left.W=0.60 ; p=1.49^{-6}\right)$ and Franschhoek $(\mathrm{W}=$ $\left.0.46 ; p=2.39^{-9}\right)$ follows a normal distribution. Additionally, the combined dataset of $K$. proteae and $K$. capensis isolates in each population did not conform to a normal distribution
(Gouritz: $W=0.84, p=3.15^{-5} ;$ Franschhoek: $W=0.74, p=$ $\left.5.78^{-9}\right)$. Neither the Mann-Whitney $U$ test for independent groups nor the Pearson's Chi-square test could detect significant differences between the number of $K$. capensis individuals isolated from the burnt and unburnt areas $(\mathrm{U}=$ 93, $p=0.56 ; X^{2}=0.73$, df $=1, p=0.79$ ). The Pearson's Chi-square test suggested a marginally significant difference between the number of isolates in the current and previous flowering season's infructescences $\left(X^{2}=3.68\right.$, df $=1, p=$ $0.05)$, but this was not supported by the Mann-Whitney $U$ test $(U=81.5, p=0.09)$. Both tests indicated that the total number of $K$. capensis isolates was significantly lower than the number of $K$. proteae isolates obtained from each population (Gouritz: $U=455.5, p=2.44^{-7}, X^{2}=75.75$, df $=1, p=2.2^{-16}$; Franschhoek: $U=732.5, p=1.02^{-5}, X^{2}=75.97, d f=1, p=$ $\left.0.79,2.2^{-16}\right)$. 


\section{DISCUSSION}

Knoxdaviesia capensis has been isolated from numerous serotinous Protea species in South Africa (Wingfield \& Van Wyk 1993, Roets et al. 2005, 2011a). The geographic distributions of the known Protea hosts of $K$. capensis often overlap with that of $P$. repens, the host of $K$. proteae (Wingfield et al. 1988), yet this study presents the first account of $K$. capensis also occurring in $P$. repens. Given that $K$. capensis is a generalist that occupies numerous Protea species (Wingfield \& van Wyk 1993, Marais \& Wingfield 1994, Roets et al. 2005, 2011a), the ability to live in the infructescences of $P$. repens is perhaps not surprising.

The low frequency of $K$. capensis individuals isolated from $P$. repens (9.7\% in Gouritz and $12.4 \%$ in Franschhoek) illustrates the dominance of $K$. proteae in this niche. It also offers an explanation for the previous oversight of $K$. capensis in $P$. repens. This low frequency is also congruent with the suggestion that $P$. repens is not a preferred host of $K$. capensis. In vitro host exclusivity experiments conducted by Roets et al. (2011a) showed that $K$. capensis produces significantly more aerial hyphae on $1.5 \%$ Water Agar (WA) supplemented with $P$. repens material than on WA alone. However, these authors also found that when supplementing nutrient-rich $1.5 \%$ Malt Extract Agar (MEA), K. capensis grew significantly better on its natural host, $P$. neriifolia, than on $P$. repens. Indeed, compared to MEA alone, $P$. repens supplemented media "slightly inhibited" the growth of $K$. capensis. These results suggest that although $K$. capensis is able to utilize $P$. repens as a substrate, it is not the preferred host of this species. However, the low level of occurrence of $K$. capensis in $P$. repens is unlikely to be due to inadequate nutrition, but more likely to be attributable to competition between $K$. capensis and other ophiostomatoid species, specifically the most prevalent species, $K$. proteae. Interspecies competition is known to occur between Northern Hemisphere ophiostomatoid fungi associated with the southern pine beetle, where Ophiostoma minus consistently out-competes Ceratocystiopsis ranaculosus (Klepzig \& Wilkens 1997). Further investigation of the interactions between Knoxdaviesia species in Protea are, however, necessary to resolve this question.

An alternative explanation for the dominance of $K$. proteae over $K$. capensis in $P$. repens could be the succession of these fungi during initial colonization. The infructescences sampled from the burnt area in the Franschhoek population represent the first flowering season of those plants. Because of the absence of older infructescences, fungi in these new infructescences must have originated from sources outside the population of burnt $P$. repens trees. Protea neriifolia trees observed in the vicinity of the burnt area were most likely to be the source of the $K$. capensis colonizers. Where $K$. capensis spores from $P$. neriifolia reach new, uncolonized $P$. repens infructescences, this species is able to grow and sporulate. This is illustrated by our results from the Franschhoek sampling plot that exclusively yielded $K$. capensis (Table 1). However, once K. proteae is introduced, it apparently dominates $K$. capensis and reduces the prevalence of that species. However, $K$. capensis individuals were also isolated from mature $P$. repens plants in the unburnt area as well as from new and old infructescences in the Gouritz population. This implies that $K$. capensis can survive in a $P$. repens population even though $K$. proteae is dominant. Statistically, however, this study does not offer support for the premise of succession, since there was no difference in the number of $K$. capensis individuals isolated from infructescences of different ages (Gouritz) or burnt and unburnt areas (Franschhoek). However, the low numbers of $K$. capensis individuals found in this study, preclude us from completely disregarding the possibility that a succession of species could occur.

Roets et al. (2009b) hypothesized that the specificity of ophiostomatoid fungi to different Protea species may be more dependent on the vectors associated with the fungi than the specificity of the fungus to the Protea host. Results of recent studies (Roets et al. 2011a), including those of the present investigation, suggest that vectors are not a primary factor underlying specificity. Knoxdaviesia capensis is clearly capable of growing in $P$. repens infructescences and has the opportunity of being vectored to this suitable habitat. The apparent difference in prevalence of the two Knoxdaviesia species in $P$. repens must, therefore, be determined by other factors, the most plausible being interspecies competition. Future studies should consider the timing of colonization, and the interaction between and the potential effects that these Knoxdaviesia species may have on each other's growth.

\section{ACKNOWLEDGEMENTS}

We thank the Western Cape Nature Conservation Board for supplying the necessary collection permits and the National Research Foundation (NRF) and the Department of Science and Technology (DST)-NRF Centre of Excellence in Tree Health Biotechnology (CTHB) for financial support.

\section{REFERENCES}

Aylward J, Dreyer LL, Steenkamp ET, Wingfield MJ, Roets F (2014a) Panmixia defines the genetic diversity of a unique arthropoddispersed fungus specific to Protea flowers. Ecology and Evolution 4: 3444-3455.

Aylward J, Dreyer LL, Steenkamp ET, Wingfield MJ, Roets F (2014b) Development of polymorphic microsatellite markers for the genetic characterisation of Knoxdaviesia proteae (Ascomycota: Microascales) using ISSR-PCR and pyrosequencing. Mycological Progress 13: 439-444.

Aylward J, Dreyer LL, Steenkamp ET, Wingfield MJ, Roets F (2015) Long-distance dispersal and recolonization of a fire-destroyed niche by a mite-associated fungus. Fungal Biology 119: 245-256.

Giraud T, Refrégier G, Le Gac M, de Vienne DM, Hood ME (2008) Speciation in fungi. Fungal Genetics and Biology 45: 791-802.

Katoh K, Standley DM (2013) MAFFT multiple sequence alignment software version 7 : improvements in performance and usability. Molecular Biology and Evolution 30: 772-780.

Klepzig KD, Wilkens RT (1997) Competitive Interactions among symbiotic fungi of the Southern Pine Beetle. Applied and Environmental Microbiology 63: 621-627. 
Marais GJ, Wingfield MJ (1994) Fungi associated with infructescences of Protea species in South Africa, including a new species of Ophiostoma. Mycological Research 98: 369-374.

McKillup S (2006) Statistics Explained: an introductory guide for life scientists. Cambridge: Cambridge University Press.

$R$ Core Team (2014) R: a language and environment for statistical computing. Vienna: R Foundation for Statistical Computing. http://www.R-project.org.

Roets F, Dreyer LL, Crous PW (2005) Seasonal trends in colonisation of Protea infructescences by Gondwanamyces and Ophiostoma spp. South African Journal of Botany 71: 307-311.

Roets F, de Beer ZW, Dreyer LL, Zipfel R, Crous PW, Wingfield MJ (2006) Multi-gene phylogeny for Ophiostoma spp. reveals two new species from Protea infructescences. Studies in Mycology 55: 199-212.

Roets F, Wingfield MJ, Crous PW, Dreyer LL (2007) Discovery of fungus-mite mutualism in a unique niche. Environmental Entomology 36: 1226-1237.

Roets F, Crous PW, Wingfield MJ, Dreyer LL (2009a) Mitemediated hyperphoretic dispersal of Ophiostoma spp. from the Infructescences of South African Protea spp. Environmental Entomology 28: 143-152.

Roets F, Wingfield MJ, Crous PW, Dreyer LL (2009b) Fungal radiation in the Cape Floristic Region: an analysis based on Gondwanamyces and Ophiostoma. Molecular Phylogenetics and Evolution 51: 111-119.

Roets F, Theron N, Wingfield MJ, Dreyer LL (2011a) Biotic and abiotic constraints that facilitate host exclusivity of Gondwanamyces and Ophiostoma on Protea. Fungal Biology 116: 49-61.

Roets F, Wingfield MJ, Wingfield BD, Dreyer LL (2011b) Mites are the most common vectors of the fungus Gondwanamyces proteae in Protea infructescences. Fungal Biology 115: 343-350.

Roets F, Wingfield MJ, Crous PW, Dreyer LL (2013) Taxonomy and ecology of ophiostomatoid fungi associated with Protea infructescences. In: Ophiostomatoid fungi: expanding frontiers. (KA Seifert, ZW de Beer \& MJ Wingfield, eds): 177-187. [CBS Biodiversity Series no. 12.] Utrecht: CBS-KNAW Fungal Biodiversity Centre.
Spatafora JW, Blackwell M (1994) The polyphyletic origins of ophiostomatoid fungi. Mycological Research 98: 1-9.

Tamura K, Nei M (1993) Estimation of the number of nucleotide substitutions in the control region of mitochondrial DNA in humans and chimpanzees. Molecular Biology and Evolution 10: 512-526.

Tamura K, Stecher G, Peterson D, Filipski A, Kumar S (2013) MEGA6: molecular evolutionary genetics analysis version 6.0. Molecular Biology and Evolution 30: 2725-2729.

White TJ, Bruns T, Lee S, Taylor J (1990) Amplification and direct sequencing of fungal ribosomal RNA genes for phylogenetics. In: PCR Protocols: a guide to methods and applications. (A Innis, DH Gelfland, JJ Sninsky \& TJ White, eds): 315-322. San Diego: Academic Press.

Wingfield BD, Viljoen CD, Wingfield MJ (1999) Phylogenetic relationships of ophiostomatoid fungi associated with Protea infructescences in South Africa. Mycological Research 103: 1616-1620.

Wingfield MJ, Wyk PSV, Marasas WFO (1988) Ceratocystiopsis proteae sp. nov., with a new anamorph genus. Mycologia 80: 23-30.

Wingfield MJ, Seifert KA, Webber JF (1993) Ceratocystis and Ophiostoma: taxonomy, ecology and pathogenicity. St Paul, MN: American Phytopathological Society Press.

Wingfield MJ, Van Wyk PS (1993) A new species of Ophiostoma from Protea infructescences in South Africa. Mycological Research 97: 709-716. 